(2) Open Access Full Text Article

REVIEW

\title{
Lacosamide as treatment for partial epilepsy: mechanisms of action, pharmacology, effects, and safety
}

This article was published in the following Dove Press journal:

Therapeutics and Clinical Risk Management

18 September 2009

Number of times this article has been viewed

\section{Christoph Kellinghaus \\ Department of Neurology, Klinikum Osnabrück, Germany}

\begin{abstract}
Lacosamide (LCM) is a novel agent that has been developed as an antiepileptic drug. In vitro studies suggest that LCM modulates voltage-gated sodium channels by enhancing their slow inactivation. In addition, LCM seems to interact with collapsin-response mediator protein 2 and thus may mediate neuronal plasticity. LCM has an elimination half-life of 13 hours, no relevant protein binding, and does not induce or inhibit enzymes of the cytochrome P450 system. No clinically significant drug-drug interactions have been discovered as yet. Experimental data suggest anticonvulsant as well as analgesic effects. Large clinical studies have demonstrated its efficacy for treatment of patients with partial seizures. LCM is well tolerated, and the most common adverse events are unspecific central nervous system and gastrointestinal effects such as dizziness, vertigo, nausea, and headache. LCM is approved for treatment of partial seizures with or without secondary generalization in the United States and the European Union within a dose range of 200 to $400 \mathrm{mg}$ per day, administered twice daily. In addition to the oral formulations, an intravenous infusion solution is available.
\end{abstract}

Keywords: lacosamide, epilepsy, antiepileptic drug

\section{Introduction}

Epilepsy is a frequent neurological disorder that is defined as the "... enduring predisposition of the brain to generate epileptic seizures ...". ${ }^{1}$ Usually, this definition is operationalized as the occurrence of two or more unprovoked seizures. Epidemiologic studies have shown that approximately $0.5 \%$ to $1 \%$ of the general population suffer from epilepsy, ${ }^{2,3}$ with annual incidence rates of approximately 30 to 50 per 100,000 per year. ${ }^{2}$ Epilepsy is not a distinct disease entity, but a common final pathway of a large variety of different etiologies. It can be described as the repetitive occurrence of abnormal bioelectrical synchronization of a large number of neurons leading to temporary dysfunction of one or more brain areas.

Application of antiepileptic drugs (AEDs) is the mainstay of treatment for most patients. Although almost $50 \%$ of the patients become seizure free with the first AED regardless of the agent, ${ }^{4}$ a substantial proportion of patients still have inadequate seizure control in spite of treatment with currently available AEDs. Therefore, there is still a need for new AED with enhanced effectiveness, tolerability, and/or pharmacokinetic properties. $^{5}$

Lacosamide (LCM) is a novel AED that has recently been licensed for adjunctive therapy of partial or secondary generalized seizures in the US as well as many European countries. This review summarizes the available pharmacological and clinical data regarding this new agent.
Correspondence: Christoph Kellinghaus Department of Neurology, Klinikum Osnabrück, Am Finkenhügel I, 49076 Osnabrück, Germany Tel +49 (0) 54I 405650 I

Fax +49 (0) 54I 4056599

Email christoph.kellinghaus@klinikum-os.de 


\section{Chemistry and mechanisms of action}

LCM (formerly referred to as SPM927, Harkoseride, or ADD 234037), is the leading drug of a novel class of AEDs termed functionalized amino acids ${ }^{6}$ which have been screened for anticonvulsant properties. ${ }^{7-10}$ The active substance is (R)-2-acetamido-N-benzyl-3-methoxyproionamide (see Figure 1). It is a white to yellow crystalline powder with a molecular weight of $250.30 \mathrm{Da}$ and a melting point of 143 to $144^{\circ} \mathrm{C}$ that has high water solubility $(20.1 \mathrm{mg} / \mathrm{mL}$ in phosphate-buffered saline). ${ }^{8,9}$ The S-stereoisomer was much less potent in preclinical studies ${ }^{11}$ and has not entered more advanced phases of drug development.

Extensive binding studies have shown that neither LCM nor its metabolites significantly bind to any of the known binding sites of other anticonvulsant or analgesic agents. ${ }^{12}$ In addition, there was no influence on uptake or metabolism of one of the major neurotransmitters. ${ }^{8}$ In spite of clear anticonvulsant properties, the molecular basis of these properties remained unclear for relatively long time. However, current experimental data suggest a dual mechanism of action: a) modulation of the slow inactivation of sodium channels, and b) modulation of collapsin-response mediator protein 2 (CRMP-2)-mediated neurotrophic signals.

\section{Modulation of the slow inactivation of sodium channels}

Early electrophysiologic studies have shown that LCM mildly reduces the spike frequency evoked by somatic current injection but did not change spike amplitude or duration. ${ }^{12}$ These findings were in contrast to the typical findings seen with classical sodium channel-blocking agents such as phenytoin and carbamazepine, but suggested a modulation of voltage-gated sodium channels (VGSC) of a different type.

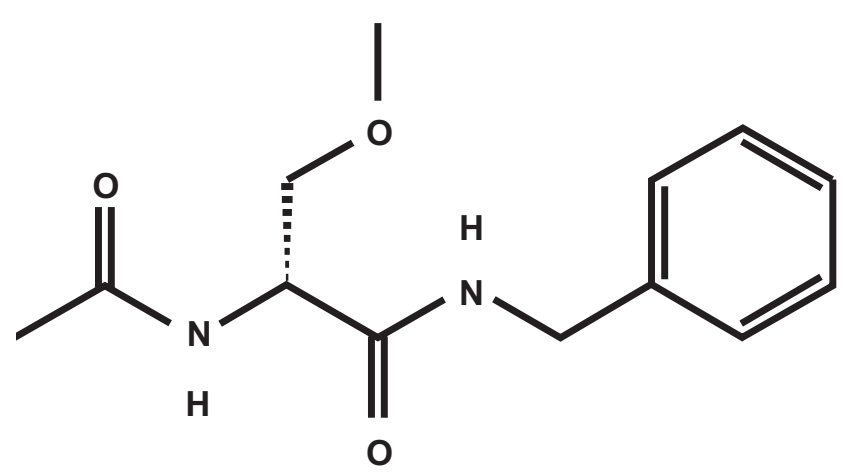

Figure I Chemical structure of lacosamide.
In addition, LCM showed a 25\% displacement of an agent binding to VGSC site 2. Moreover, LCM seemed to interfere preferentially with seizure spread and spontaneous action potentials without having any influence on voltage-gated Potassium channels or calcium channels. ${ }^{12,13}$ Finally it could be demonstrated that LCM selectively enhances slow inactivation of VGSC, whereas classical sodium channel blocking agents produce fast inactivation and/or delay recovery from fast inactivation of VGSC without any influence on slow inactivation. ${ }^{14}$ At resting potential, VGSC can be opened by depolarization of the membrane potential below a critical threshold. The opening leads to influx of sodium ions into the cell. Within milliseconds, the channel closes again and is now in the fast inactivated state. After repolarization of the membrane potential, the channel goes into resting state and is again available for opening. In contrast to that, a slight and prolonged depolarization can bring the VGSC into the slow inactivated state. This process takes seconds to minutes. ${ }^{8}$ Whereas classical AEDs enhance the fast inactivated state, LCM seems to enhance the slow inactivated state by altering the voltage-dependence of the VGSC subunit arrangement. Thus LCM reduces the ability of (epileptic) neurons to sustain prolonged firing bursts by regulating the long-term availability of VGSCs. ${ }^{8,14}$

\section{Modulation of CRMP-2-mediated neurotrophic signals}

Proteomic affinity labeling methods and subsequent radioligand binding experiments have demonstrated CRMP-2 as a binding partner for LCM. ${ }^{8}$ Proteins of the CRMP-family seem to be involved in developmental processes of the nervous system. CRMP-2 mediates the transduction of neurotrophic signals to neuronal response and thus influences axonal sprouting and as well as neuronal differentiation. ${ }^{15}$ Moreover, CRMP-2 seems to be reduced in human hippocampal slices from patients with refractory epilepsy, but not in nonepileptic control patients. ${ }^{16} \mathrm{LCM}$ inhibits those effects of neurotrophins on axonal outgrowth that are CRMP-2-mediated. ${ }^{8}$ There is additional indirect evidence for the role of LCM CRMP-2-modulation, since CRMP-2 mediates downregulation of N-methyl-D-aspartate (NMDA)-receptor subtype NR2B - a receptor subtype that seem to play a role in epileptogenesis. ${ }^{17}$

\section{Pharmacokinetics, drug interactions}

Basic pharmacological properties were assessed in phase I studies with healthy volunteers. ${ }^{10,18}$ Following oral administration, single doses of LCM were rapidly 
and almost completely absorbed. ${ }^{10,18}$ Maximum plasma concentration was reached between 1 and 4 hours after intake (mean: 1.5 hours), with linear increase of plasma concentration with dose (400 mg: $8.7 \pm .8 \mu \mathrm{g} / \mathrm{mL} ; 600 \mathrm{mg}$ $14.3 \pm 2.3 \mu \mathrm{g} / \mathrm{mL}, 800 \mathrm{mg}: 19.0 \pm 4.8 \mu \mathrm{g} / \mathrm{mL}){ }^{18,10}$ Elimination half-life was approximately 13 hours. Multiple dosing did not change the basic pharmacokinetic properties. ${ }^{18}$ Concomitant administration of food did not influence time to maximum plasma concentration or the area under the plasma-concentration-time curve (AUC).${ }^{19}$ Protein binding was $<15 \%$. $^{18,20}$ There was low intra- as well as inter-subject variability even across different age groups and gender, with subjects above 65 years of age having only slightly shorter interval to maximum concentration and higher AUC. ${ }^{21}$ Steady-state plasma levels were achieved after three days of repeated oral administration. A proportion of LCM $(\sim 30 \%)$ is metabolized to a O-desmethyl-metabolite that seems to have no pharmacological acitivity. ${ }^{22,23} \mathrm{LCM}$ and its metabolites are eliminated primarily by kidney. ${ }^{22,23}$ However, there was only a $20 \%$ increase of AUC in patients with mild to moderate renal impairment (ie, creatinin clearance $=30$ to $80 \mathrm{~mL} / \mathrm{min}$ ), and a $60 \%$ increase in patients with severe renal impairment. ${ }^{22}$ Administration of LCM to extensive or poor metabolizers of the cytochrome $\mathrm{P} 450$ subsystem $2 \mathrm{C} 19$ showed that there is no relevant effect on metabolization and elimination of LCM by this system. ${ }^{20}$ In spite of this fact, there is a $50 \%$ to $60 \%$ increase in the AUC in patients with moderate hepatic impairment. ${ }^{22}$ Therefore, caution is advised in patients with hepatic disease.

These properties suggest that there is a low potential for pharmacokinetic interactions with other AEDs or other drugs. Specific trials showed no interaction of LCM and valproate, carbamazepine ${ }^{24}$ and metformin. ${ }^{25}$ In addition, LCM did not interact with digoxin, omeprazol, estradiol or levonorgestrel. ${ }^{20}$ There was no effect of LCM on concomitant AED plasma levels (carbamazepine, lamotrigine, levetiracetam, phenytoin, zonisamide, gabapentin, topiramate) in patients enrolled in phase I, phase II, and phase III studies ${ }^{20,26-28}$ with the exception of a mild decrease of the monohydroxy-derivative of oxcarbazepine without clinical relevance (mean decrease $4.2 \mu \mathrm{g} / \mathrm{mL}$ ) in one of the phase-III trials. ${ }^{28}$ In

Table I Pharmacokinetic profile

\begin{tabular}{|c|c|}
\hline Bioavailability & $\sim 100 \%$ \\
\hline $\mathrm{t}_{\max }(\mathrm{h}, \text { median/range })^{\mathrm{a}}$ & $1.5(I-4)$ \\
\hline $\mathrm{C}_{\max }(\mu \mathrm{g} / \mathrm{mL})$ & $8.7( \pm 1.8)$ \\
\hline $\operatorname{A\cup C}(\mu \mathrm{g} \cdot \mathrm{h} / \mathrm{mL})$ & $143( \pm 27)$ \\
\hline$t_{1 / 2}(h)$ & 13 \\
\hline Protein-binding & $<15 \%$ \\
\hline Distribution volume & $\sim 0.6 \mathrm{~L} / \mathrm{kg}$ \\
\hline Relation metabolization:unchanged elimination & $60: 40$ \\
\hline Active metabolites & no \\
\hline Elimination & renal (substance and metabolites) \\
\hline Influence of concomitant food & no \\
\hline Induction/inhibition of Cytochrome $P 450$ subsystems: & no \\
\hline $\mathrm{AUC} / \mathrm{C}_{\max }$ in healthy elderly & $\sim+20 \%$ compared to young subjects \\
\hline $\mathrm{AUC} / \mathrm{C}_{\max }$ in mild/moderate renal impairment & $\sim+25 \%$ compared to healthy subjects \\
\hline $\mathrm{AUC} / \mathrm{C}_{\max }$ in severe renal impairment & $\sim+60 \%$ compared to healthy subjects \\
\hline $\mathrm{AUC} / \mathrm{C}_{\max }$ in mild/moderate hepatic impairment & $\sim+50 \%$ to $60 \%$ compared to healthy subjects \\
\hline Elimination by hemodialysis & complete \\
\hline Relevant drug-drug interaction with anticonvulsants & no \\
\hline $\begin{array}{l}\text { Relevant drug-drug interaction with metformin, digoxin, } \\
\text { estradiol, levonorgestrel, omeprazol }\end{array}$ & no \\
\hline Mean plasma concentration in patients completing & $4.99 \mu \mathrm{g} / \mathrm{mL}$ (LCM 200 mg/day) \\
\hline a randomized, multicenter trial & $9.35 \mu \mathrm{g} / \mathrm{mL}$ (LCM 400 mg/day) \\
\hline
\end{tabular}

${ }^{2} 400 \mathrm{mg}$ single dose in healthy male volunteers.

Abbreviations: $\mathrm{t}_{\text {max }}$, time to maximum plasma concentration; $\mathrm{C}_{\text {max }}$, maximum plasma concentration; $\mathrm{AUC}$, area under the plasma-concentration-time-curve; $\mathrm{t}_{1 / 2}$, elimination half-life. 
contrast to that, a population pharmacokinetic analysis of the phase III studies showed that enzyme-inducing AEDs such as phenytoin, carbamazepin, or phenobarbital reduced the overall systemic exposure to LCM by $15 \%$ to $20 \% .^{22}$ This information was added to the physician's prescription information, but the analysis itself has not yet been published in detail. Its clinical relevance remains to be elucidated.

\section{Experimental data on efficacy and safety/tolerability}

LCM was screened for anticonvulsant effects in range of animal models of seizures and epilepsy. In these investigations, it demonstrated a unique profile similar to some of the newer AEDs, but with several differences. Using the Frings audiogenic seizures-susceptible mouse model, LCM was protective with an ED50 of $0.63 \mathrm{mg} / \mathrm{kg}$ (intraperitoneally injected). ${ }^{29}$ The maximal electroshock model (MES) is regarded as screening instrument for inhibition of seizure spread. ${ }^{30}$ LCM was effective in the MES in rats as well as in mice, ${ }^{8,31}$ demonstrating its potential to prevent secondary generalized seizures. The 6-Hz psychomotor seizure test seems to model therapy-resistant epilepsy ${ }^{32}$ and is regarded as complementary to the MES model because of different sensitivities to distinct classes of AEDs. In contrast to classical VGSC agents, LCM was very effective in the 6-Hz psychomotor seizure test with an ED50 of $9.99 \mathrm{mg} / \mathrm{kg} .{ }^{8,33} \mathrm{In}$ this model, there was also a significant synergistic effect with carbamazepine and levetiracetam. ${ }^{8}$

LCM did not provide protection against seizures provoked by most chemoconvulsants such as bicuculline, picrotoxin and pentylenetetrazol. ${ }^{8,29}$ However, LCM elevated the seizure threshold in the metrazol-seizure threshold test ${ }^{8,29}$ and prevented seizures and death in the NMDA-induced convulsion test in mice. $^{31}$

In addition, LCM demonstrated efficacy in a model screening for antiepileptic (in contrast to anticonvulsant) properties of a medication. In the electrical rapid hippocampal kindling model, ${ }^{34}$ animals receive repetitive electrical stimulation of the hippocampal area successively decreasing the seizure threshold for following stimuli. LCM in a dosedependent fashion reduced seizure duration seizure severity and after discharge duration using doses from $7 \mathrm{mg} / \mathrm{kg}$ to $25 \mathrm{mg} / \mathrm{kg} .{ }^{31}$

In the cobalt/homocysteine model for self-sustaining status epilepticus in rats, LCM was able to dose-dependently prevent generalized tonic-clonic seizures (ED 50: $45.4 \mathrm{mg} / \mathrm{kg}$ ). The co-administration of diazepam markedly potentiated the

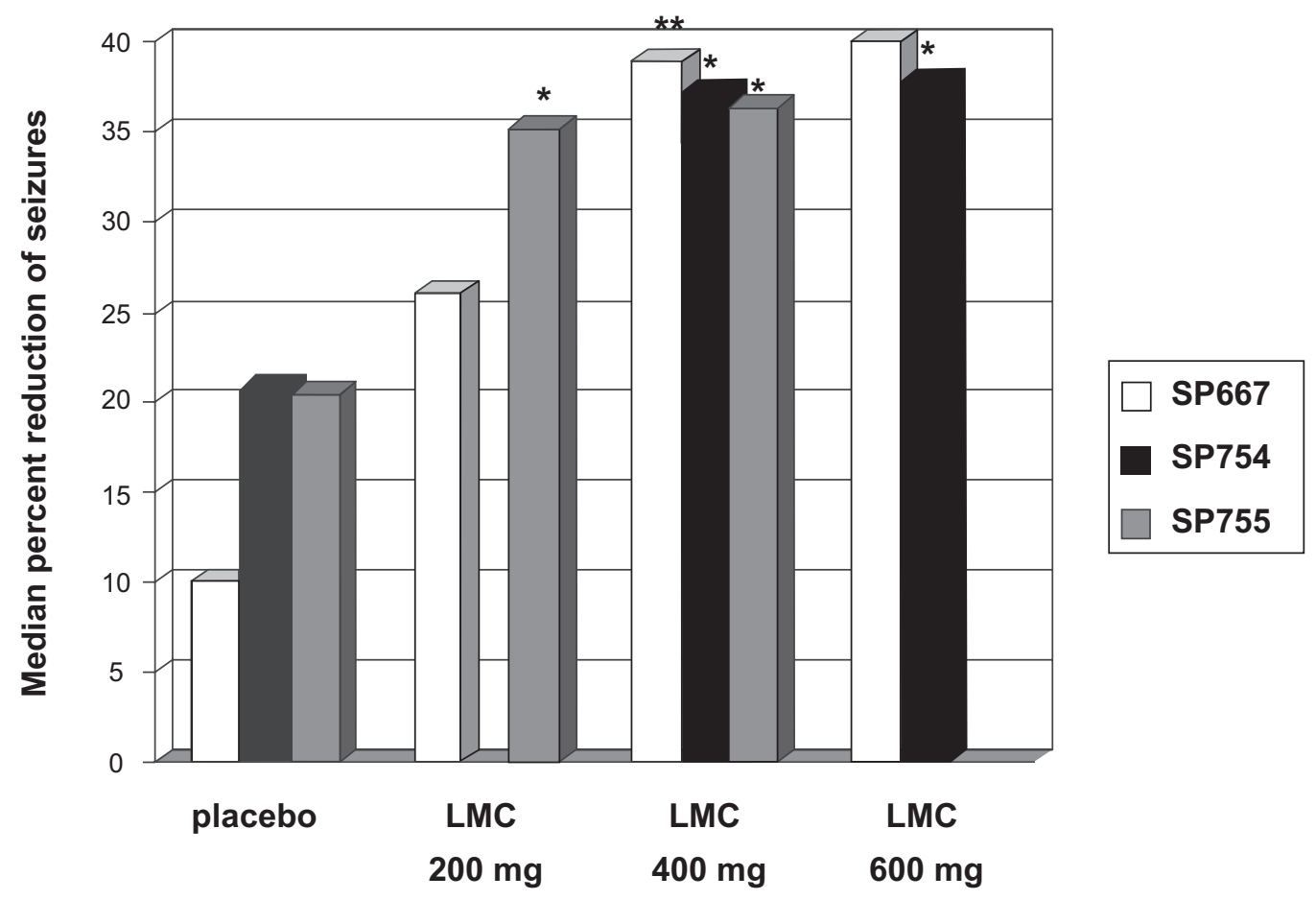

Figure 2 Efficacy of lacosamide (LCM) in partial epilepsy. Summary of the results of the phase-III studies of LCM as add-on treatment of patients with partial seizures with or without secondary generalization - primary endpoint I: reduction in seizure frequency per 28 days from baseline to maintenance.

Notes: **P $<0.01 * \mathrm{P}<0.05$ 


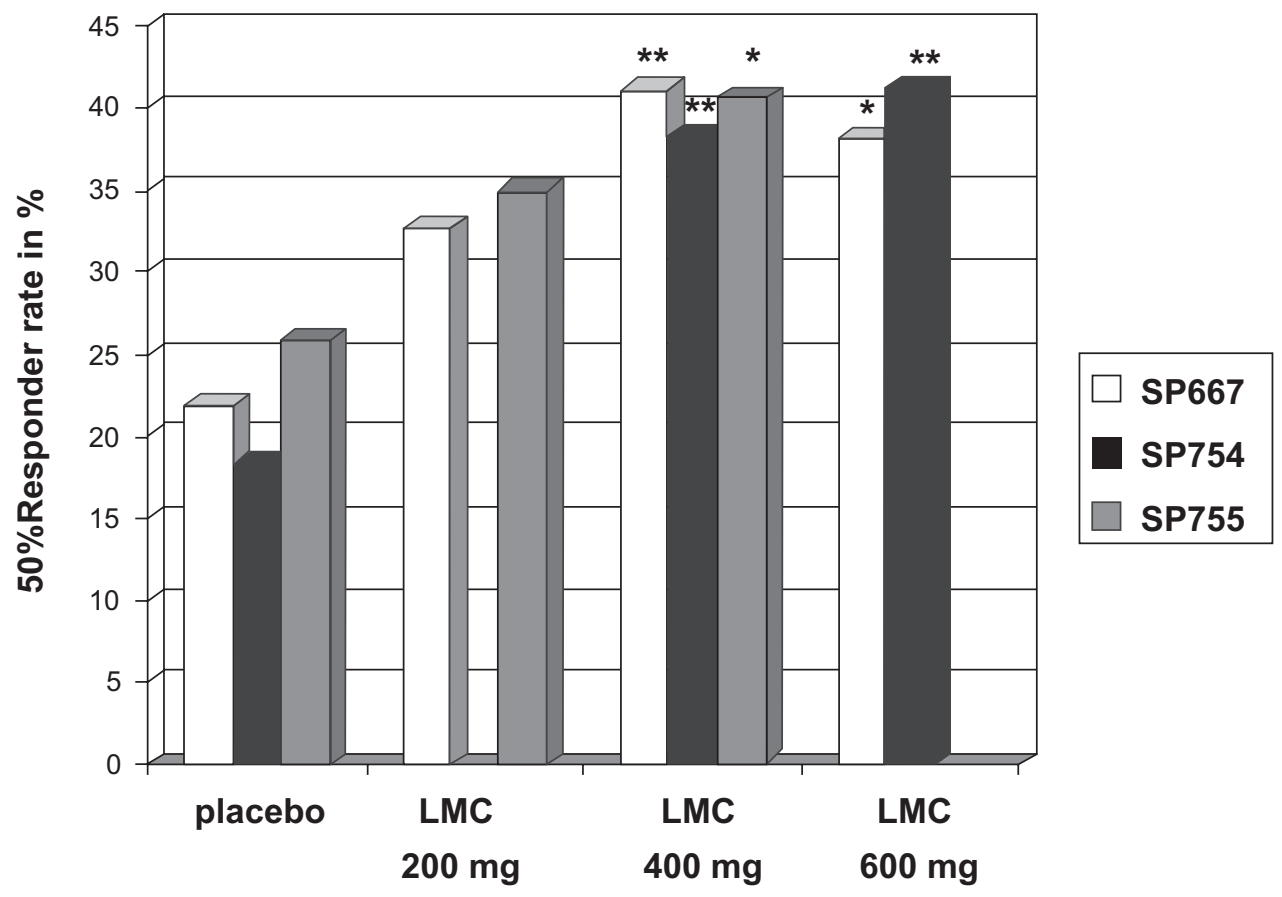

Figure 3 Efficacy of lacosamide (LCM) in partial epilepsy. Summary of the results of the phase III studies of LCM as add-on treatment of patients with partial seizures with or without secondary generalization - primary endpoint 2: responder rate, defined as reduction of at least $50 \%$ in seizure frequency from baseline to maintenance. Notes: $* * \mathrm{P}<0.01 * \mathrm{P}<0.05$

effect of LCM and reduced the ED50 by more than $90 \%$ to $3.85 \mathrm{mg} / \mathrm{kg}^{3}{ }^{31}$

\section{Clinical efficacy and use in epilepsy}

Early trials involving patients with epilepsy were open label. Their results have been published only in abstract form. ${ }^{27,35}$ In one trial, ${ }^{27}$ doses were increased from 200 to $600 \mathrm{mg} /$ day in weekly steps of $200 \mathrm{mg}$. Eleven of 13 patients reached the maximum dose of $600 \mathrm{mg} /$ day, with the most common adverse effects of dizziness, headache, ataxia and nystagmus (at least $10 \%$ of the patients). The following trial ${ }^{35}$ included 91 subjects with partial seizures who are taking one or two concomitant AEDs. After a baseline of 4 weeks, LCM was titrated in increments of $100 \mathrm{mg} /$ week to the individual maximum tolerated dose (MTD) and then kept stable for 4 weeks. The MTD was between 400 and $600 \mathrm{mg}$ in approximately $50 \%$ of the patients, with a median MTD of $300 \mathrm{mg} /$ day. In 86 patients, seizure data were complete. During the 4 -week maintenance phase, there was a seizure reduction of at least $50 \%$ in $33 \%$ of the patients, and $10 \%$ of the patients remained seizure free.

Finally, 3 large randomized controlled trials were conducted that provided the mandatory efficacy and safety data required for licensing of LCM. The results of 2 of these (SP 667, SP 755) have been published as original communications in peer-reviewed journals. ${ }^{26,28}$ The results of the third trial (SP754) are available only as an abstract. ${ }^{36}$

The first large phase III trial ${ }^{26}$ was conducted as an international, multicenter, double-blinded, placebo-controlled, randomized trial with 3 treatment arms (LCM $200 \mathrm{mg} /$ day, LCM $400 \mathrm{mg} /$ day, LCM $600 \mathrm{mg} /$ day) and 1 placebo arm. Randomization was performed in a 1:1:1:1 ratio. Eligible patients must have had partial seizures for at least the prior 2 years despite treatment with at least 2 AEDs and a stable AED regimen for the last 4 weeks before enrollment. Patients were excluded when they fulfilled the typical exclusion criteria for trials with investigational AEDs such as history of alcohol and drug abuse, nonepileptic seizures, history of idiosyncratic drug reactions, relevant medical or psychiatric diseases. During the prospective baseline phase, subjects had to have at least 4 partial-onset seizures per 28 days on average. If the subjects were eligible for randomization, a 6-week titration period and a 12-week maintenance period followed. Titration was in steps of $100 \mathrm{mg} /$ week. Primary outcome variables were reduction in seizure frequency per 28 days from baseline to maintenance, and responder rate (ie, rate of subjects with at least $50 \%$ reduction of seizure frequency) from baseline to maintenance. Of the 497 patients who entered the baseline period, 421 were randomized to one of the four treatment arms. The intention-to-treat analysis (ITT) showed a median 
percent reduction of $40 \%$ in the $600 \mathrm{mg} / \mathrm{day}, 39 \%$ in the $400 \mathrm{mg} /$ day, $26 \%$ in the $200 \mathrm{mg} /$ day and $10 \%$ in the placebo group. Statistical significance was reached only for the 600 $\mathrm{mg} /$ day $(P=0.0023)$ and the $400 \mathrm{mg} /$ day $(P=0.0084)$ groups. Compared to the responder rate of the placebo group $(22 \%)$, the responder rate of the $600 \mathrm{mg} /$ day group $(38 \%, P=0.0141)$ and of the $400 \mathrm{mg} /$ day group ( $41 \%, P=0.0038)$ was significantly higher. The difference to the $200 \mathrm{mg}$ /day group (33\%, $P=0.089)$ did not reach statistical significance. A total of 7 patients were seizure free during the maintenance period $(1 / 107$ in the $200 \mathrm{mg} /$ day group, $5 / 108$ in the $400 \mathrm{mg} /$ day group, and $1 / 106$ in the $600 \mathrm{mg} /$ day group, 0/97 in the placebo group). The retention rate was not one of the prespecified outcome parameters. However, the retention rate is an important variable because it combines aspects of efficacy as well as of tolerability. Eighty-six of 97 patients randomized to placebo (89\%), 85 of 107 patients randomized to LCM $200 \mathrm{mg} /$ day (79\%), 80 of 108 patients randomized to LCM $400 \mathrm{mg} /$ day (74\%), and 61 of 106 patients randomized to LCM $600 \mathrm{mg} /$ day (57\%) completed the trial.

The second trial ${ }^{28}$ was also designed as a multinational, double-blind, randomized, placebo-controlled trial, but with 2 treatment arms (LCM $200 \mathrm{mg} /$ day, LCM $400 \mathrm{mg} /$ day) and 1 placebo arm, with a 1:1:1-randomization into the different arms. Baseline period, and eligibility and exclusion criteria were the same as in the first trial. However, the titration phase was 4 weeks, but with the same incremental steps (100 mg/week). Maintenance phase was 12 weeks as above. Again, primary outcome parameters were change in seizure frequency from baseline to maintenance period, and the $50 \%$ responder rate.

Of the 584 patients entering the baseline period, 485 patients were randomized. However, only those 477 patients that received at least 1 dose of trial medication were included in the ITT analysis. The ITT analysis showed a median percent reduction of seizure frequency of $36 \%$ for the LCM $400 \mathrm{mg} /$ day group, 35\% for the LCM $200 \mathrm{mg}$ /day group, and 21\% for the placebo group. The differences for both treatment arms against placebo reached statistical significance $(P=0.02$ for LCM $200 \mathrm{mg} /$ day, $P=0.03$ for LCM $400 \mathrm{mg} /$ day). The 50\% responder rate was $41 \%$ for the LCM $400 \mathrm{mg}$ /day group, $35 \%$ for the LCM $200 \mathrm{mg}$ /day group, and 26\% for the placebo group. Only the difference between the LCM $400 \mathrm{mg} /$ day group and placebo was statistically significant. Among those completing the maintenance period, $3.6 \%$ of the patients receiving LCM $200 \mathrm{mg} /$ day, 2.4\% of the patients receiving $400 \mathrm{mg} /$ day, and $2.1 \%$ of the patients receiving placebo were seizure free. Hundred forty-seven of 163 patients randomized to placebo (90\%), 136 of 163 patients randomized to LCM $200 \mathrm{mg} /$ day (83\%), and 122 of 159 patients randomized to LCM $400 \mathrm{mg} /$ day (76\%) completed the study.

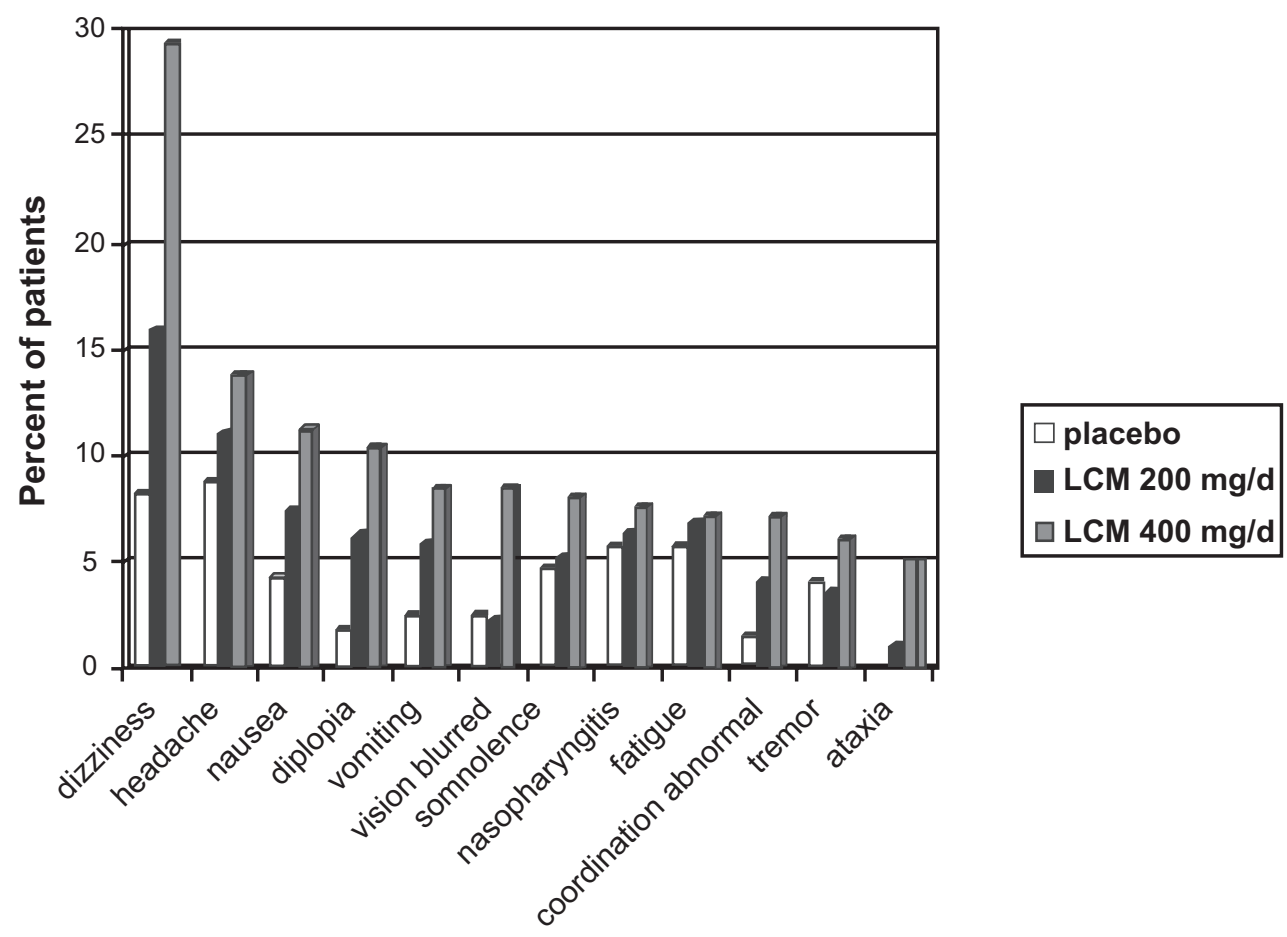

Figure 4 Tolerability of lacosamide (LCM) in patients with epilepsy. Incidence of treatment-emerging events in patients receiving placebo, LCM $200 \mathrm{mg} /$ day and LCM $400 \mathrm{mg} / \mathrm{day}$ during phase III studies for treatment of partial epilepsy (safety sets of studies SP667, SP754, and SP755). 
The third study ${ }^{36}$ was also designed as multicenter, double-blind, randomized, placebo-controlled study but was conducted solely in the US. The same inclusion criteria and primary outcome variables as in the 2 other large studies, and the same length of baseline, titration, and maintenance periods as in the first trial were used. A total of 405 patients were randomized in a 1:2:1 proportion to placebo, LCM $400 \mathrm{mg} /$ day and LCM $600 \mathrm{mg} /$ day. In the ITT analysis, a median reduction of seizure frequency of $21 \%$ for placebo, $37 \%$ for LCM $400 \mathrm{mg} /$ day and $38 \%$ for LCM $600 \mathrm{mg} /$ day was found. The $50 \%$ responder rate was $18 \%$ for the placebo group, $38 \%$ for the LCM $400 \mathrm{mg}$ /day group and $41 \%$ for the LCM $600 \mathrm{mg} /$ day group. The differences between the active arms and the placebo arm were significant $(P<0.01)$. No patient of the placebo-group, 4 patients of the LCM $400 \mathrm{mg}$ /day group (2.5\%), and 5 patients of the LCM $600 \mathrm{mg} /$ day group (8\%) were seizure-free throughout the maintenance period. Retention rate was 95/104 (91\%) for the placebo group, 160/201 (80\%) for the LCM $400 \mathrm{mg} /$ day group, and 62/97 (64\%) in the LCM $600 \mathrm{mg}$ /day group.

Patients who participated in the large randomized controlled trials could opt for transfer into open-label extension trials. After titration to a common starting dose of $200 \mathrm{mg} /$ day, the patient could receive between $100 \mathrm{mg} /$ day and $800 \mathrm{mg} / \mathrm{day}$, according to the individual response. Median seizure reduction compared to baseline was $43 \%$ after 24 weeks. ${ }^{37}$

In summary, LCM showed a dose-dependently increasing efficacy and decreasing retention rate. Whereas LCM $200 \mathrm{mg}$ /day failed to show a statistically significant effect compared to placebo in some of the trials and primary outcome parameters but had the best retention rates, LCM $600 \mathrm{mg} /$ day had the lowest retention rates with the efficacy not markedly better than LCM $400 \mathrm{mg}$ /day. Therefore, doses about $400 \mathrm{mg}$ seem to show the most favorable trade-off between efficacy and tolerability.

\section{Safety, tolerability, and adverse effects}

A study investigating the median tolerated dose with titration steps of $100 \mathrm{mg} /$ week $^{35}$ in 91 patients showed that the most frequent adverse events were related to central nervous system (CNS) effects such as dizziness (57\%), diplopia (23\%), fatigue (18\%), and somnolence (19\%). Adverse events concerning other body systems were mentioned not more than once and included syncope, asthenia, dyspepsia, bundle branch block, anxiety, erythematous rash, and abnormal vision. However, only $12 \%$ of the patients withdrew due to adverse events (headache $\mathrm{n}=3$, dizziness $\mathrm{n}=2$, hypoaesthesia $\mathrm{n}=2$, ataxia $\mathrm{n}=1$, seizure $\mathrm{n}=1$ ). Median tolerated dose was $300 \mathrm{mg} /$ day, most common maximum tolerated dose was $600 \mathrm{mg}$.

In the large phase III trials, the most frequent dose-related adverse events ( $>10 \%$ of patients) were seen in the CNS (dizziness, headache, fatigue, ataxia, abnormal vision, somnolence, ataxia, and diplopia) and gastrointestinal (nausea, vomiting) and represent the typical dose-dependent effects of AEDs and other CNS-acting drugs. ${ }^{26,28,36,38-40}$ Withdrawal because of adverse events occurred in 5\% to $14 \%$ of the placebo groups, $6 \%$ to $11 \%$ of the LCM $200 \mathrm{mg}$ /day-groups, $11 \%$ to $24 \%$ of the LCM $400 \mathrm{mg} /$ day groups and $27 \%$ to $42 \%$ of the LCM $600 \mathrm{mg} /$ day groups. Adverse events leading to discontinuation in more of $1 \%$ of the patients were diplopia, tremor, vertigo, nausea, vomiting, dizziness, abnormal coordination, and nystagmus. Serious adverse events occurred in 3 to $7 \%$ in the placebo group, $3 \%$ to $9 \%$ in the $\mathrm{LCM}$ $200 \mathrm{mg}$ /day group, $5 \%$ to $10 \%$ in the LCM $400 \mathrm{mg}$ /day group, and $3 \%$ to $10 \%$ in the LCM $600 \mathrm{mg}$ /day group. The serious adverse events seen in more than 1 patient were (worsening of) seizures, psychotic disorders, dizziness, vomiting, accident, and nystagmus. ${ }^{26,28}$ The long-term open-label extension trials showed a similar profile of mainly mild to moderate CNS and gastrointestinal effects with a drop-out rate due to adverse events in $11 \%$ to $17 \%$ of the patients. ${ }^{41,42}$

Although the phase I and phase III trials did not show a significant change of PR and QTc intervals, ${ }^{43}$ ECG data of the large randomized trials showed a mild increase in mean PR interval compared to baseline that seemed to be dose-related ( 4.2 to $12.3 \mathrm{~ms}$ at a dose of $400 \mathrm{mg}$ / day). ${ }^{26,28,36,38-40}$ However, this was not clinically relevant as only 4 of 941 patients of the epilepsy studies, ${ }^{26,28,36}$ and in none of the patients did this PR change lead to drop out. In the diabetic painful neuropathy studies, there was a treatment-emergent first-grade atrioventricular block in $2 \%$ to $8 \%$ of the patients receiving LCM, but also in $6 \%$ of the placebo group in 1 trial, ${ }^{39}$ and in approximately $2 \%$ in both LCM-receiving groups and placebo. Changes in QTe were not reported. ${ }^{26,28,36,38,39}$ There was no evidence for relevant changes of body weight. ${ }^{39}$

\section{Lacosamide as intravenous solution}

LCM iv solution was developed early because of the relatively high water solubility of the agent. The available formulation is a $10 \mathrm{mg} / \mathrm{L}$ isotonic solution $(\mathrm{pH} 3.5$ to 5). It is stable at room temperature, does not need protection from light, and can be administered without dilution or other preparation. ${ }^{44}$ Phase-I trials with healthy volunteers showed bioequivalence as measured by the area 
under the curve (AUC) and maximal concentration $\left(\mathrm{C}_{\max }\right)$ between LCM $200 \mathrm{mg}$ taken orally or per intravenous infusion of 30 minutes and 60 minutes duration. ${ }^{45,46}$ To demonstrate safety and tolerability, a randomized, doubleblind, double-dummy trial was performed. ${ }^{44}$ Patients were recruited from an ongoing open-label extension trial. They had to be on a stable dose of oral LCM and the concomitant AEDs for at least 4 weeks. Patients were randomized (2:1) to receive either iv LCM and placebo tablets twice daily, or iv placebo and LCM tablets twice daily. Intravenous LCM was administered in 30 minutes in one group, and in 60 minutes in the other group. LCM doses ranged from $200 \mathrm{mg}$ to $600 \mathrm{mg} / \mathrm{day}$, the majority of the patients receiving $200 \mathrm{mg}$ to $300 \mathrm{mg} \mathrm{LCM}$ as single dose. There was no significant difference in the number and types of treatmentemergent adverse events between groups. Pharmacokinetic parameters also did not differ.

A second trial was designed as an open-label trial. ${ }^{47}$ Patients were also recruited from an ongoing open-label extension trial of oral LCM, with the same inclusion and exclusion criteria as the previously mentioned trial. Five cohorts were planned with varying infusion rates $(30,15$, or 10 minutes) and duration of dosing (2 to 5 days). A safety monitoring committee reviewed data from each completed cohort prior to initiation of the subsequent cohort. Data of 4 cohorts have been published in abstract form to date. They included 160 patients ( 30 minutes infusion: $n=40 ; 160$ total infusions; 15 minutes infusion: $\mathrm{n}=100,747$ total infusions; 10 minutes infusion: $n=20,162$ total infusions). Sociodemographic data were similar across the cohorts. More than half of the patients of each cohort received a daily dose of LCM ranging from 200 to $400 \mathrm{mg}$, a third to one half of the patients received 500 to $600 \mathrm{mg}$, and 7 patients of the 15-minutes group received 700 to $800 \mathrm{mg}$ per day. Across the 10 -minutes and 15 -minutes cohorts, $71 \%$ of the subjects received iv treatment over 3 to 5 days.

There was 1 serious adverse event reported. One subject in the 15-minutes group experienced bradycardia for 4 minutes during the second day of LCM iv (300 mg/day) that was estimated as possibly related to the infusion. The infusions on day 1 of LCM iv had been uneventful. The most common adverse events were headache (5\% to $8 \%$ of all subjects), and dizziness ( $5 \%$ to $8 \%$ ). The severity was rated as mild or moderate, and in rated as unrelated to the infusions in $80 \%$ of the patients. A small increase of PR time in ECG was noted that did not differ across cohorts. There was no

Table 2 Summary of phase III randomized, double-blind, placebo-controlled studies for add-on therapy of lacosamide (LCM) in patients with partial epilepsy

\begin{tabular}{|c|c|c|c|}
\hline Study & SP667 & SP755 & SP754 \\
\hline Published as & $\begin{array}{l}\text { original report } \\
\left(\text { Ben-Menachem et } \mathrm{al}^{26} \text { ) }\right.\end{array}$ & $\begin{array}{l}\text { original report } \\
\left(\text { Halasz et } \mathrm{a}^{28}\right)\end{array}$ & $\begin{array}{l}\text { poster } \\
\left(\text { Chung et } \mathrm{a}^{36} \text { ) }\right.\end{array}$ \\
\hline $\begin{array}{l}\text { Number of subjects } \\
\text { randomized }\end{array}$ & 421 & 485 & 405 \\
\hline Time-scale & $\begin{array}{l}8 \text { weeks prospective baseline } \\
6 \text { weeks titration } \\
\text { I } 2 \text { weeks maintenance }\end{array}$ & $\begin{array}{l}8 \text { weeks prospective baseline } \\
4 \text { weeks titration } 12 \text { weeks } \\
\text { maintenance }\end{array}$ & $\begin{array}{l}8 \text { weeks prospective baseline } \\
6 \text { weeks titration } 12 \text { weeks } \\
\text { maintenance }\end{array}$ \\
\hline Study arms & $\begin{array}{l}\text { Placebo } \\
\text { LCM } 200 \mathrm{mg} / \text { day } \\
\text { LCM } 400 \mathrm{mg} / \text { day } \\
\text { LCM } 600 \mathrm{mg} / \text { day }\end{array}$ & $\begin{array}{l}\text { Placebo } \\
\text { LCM } 200 \text { mg/day } \\
\text { LCM } 400 \text { mg/day }\end{array}$ & $\begin{array}{l}\text { Placebo } \\
\text { LCM } 400 \text { mg/day } \\
\text { LCM } 600 \text { mg/day }\end{array}$ \\
\hline Randomization scheme & $\begin{array}{l}\text { placebo, } 200 \mathrm{mg}, 400 \text { mg, } 600 \mathrm{mg} \\
\text { I:I:I:। }\end{array}$ & $\begin{array}{l}\text { placebo, } 200 \mathrm{mg}, 400 \mathrm{mg} \\
\text { I:I:I }\end{array}$ & $\begin{array}{l}\text { placebo, } 400 \mathrm{mg}, 600 \mathrm{mg} \\
\mathrm{I}: 2: \mathrm{I}\end{array}$ \\
\hline $\begin{array}{l}\text { Number of subjects } \\
\text { in ITT population }\end{array}$ & $\begin{array}{l}415 \\
\text { placebo, } 200 \mathrm{mg}, 400 \mathrm{mg}, \\
600 \mathrm{mg}: 96,107,107,105\end{array}$ & $\begin{array}{l}477 \\
\text { placebo, } 200 \mathrm{mg}, 400 \mathrm{mg}: \text { I59, } \\
\text { I60, I } 58\end{array}$ & $\begin{array}{l}402 \\
\text { placebo, } 400 \mathrm{mg}, 600 \mathrm{mg}: \text { 104, 201, } 97\end{array}$ \\
\hline $\begin{array}{l}\text { Number of subjects } \\
\text { completed }\end{array}$ & $\begin{array}{l}312 \\
\text { placebo, } 200 \mathrm{mg}, 400 \mathrm{mg}, \\
600 \mathrm{mg}: 86,85,80,61\end{array}$ & $\begin{array}{l}399 \\
\text { placebo, } 200 \mathrm{mg}, 400 \mathrm{mg}: \text { I } 4 \text { I, } \\
\text { I36, I } 22\end{array}$ & no data \\
\hline $\begin{array}{l}\text { Number of subjects } \\
\text { discontinued }\end{array}$ & $\begin{array}{l}\text { II, 22, 28, } 45 \\
(11 \%, 21 \%, 26 \%, 43 \%)\end{array}$ & $22,27,37$ (I4\%, 20\%, 23\%) & no data \\
\hline $\begin{array}{l}\text { Discontinued because } \\
\text { of adverse events }\end{array}$ & $5,16,20,32$ & $9,10,25$ & $\begin{array}{l}\text { placebo, } 400 \mathrm{mg}, 600 \mathrm{mg} \\
5 \%, 18 \%, 27 \%\end{array}$ \\
\hline
\end{tabular}

Abbreviation: ITT, intention-to-treat. 
increase in adverse event frequency with shorter infusion frequency or greater days of exposure.

\section{Summary and perspectives}

LCM is a novel AED that has been approved by the licensing authorities in the US and in the European Union for add-on treatment of partial seizures with or without secondary generalization in patients of 16 years of age or older at a daily dose of 200 $\mathrm{mg}$ to $400 \mathrm{mg}$. Its proposed mechanisms of action as well as experimental data suggest that there may be synergistic effects in combination with other AEDs. ${ }^{8}$ Its elimination half-life of 13 hours results in a comparatively easy handling with twice daily dosing independent of food intake. LCM plasma levels do not show significant variability with gender or age. In addition, there are no known relevant pharmacokinetic interactions with other AEDs or other relevant agents such as digoxin or estradiol. To date, data on efficacy and tolerability in approximately 1300 patients with epilepsy have been published..$^{48}$ These data show that LCM can effectively reduce seizure burden even in patients who have been refractory to modern AEDs such as levetiracetam, topiramate, or oxcarbazepine. Retention rates in the phase III epilepsy trials have been $75 \%$ to $85 \%$ in the treatment arms using the currently approved doses. The side effects are mainly unspecific CNS and gastrointestinal effects, and mild or moderate, and seem to be dose-dependent and associated with the titration phase. Idiosyncratic reactions have not been observed as of yet. ECG data show a dose-dependent prolongation of the PR interval of about 5 to $10 \mathrm{~ms}$ which is rarely clinically relevant. However, it is recommended that LCM should not be used in patients with a pre-existing atrioventricular block of grade 1 or 2. Changes of other ECG intervals, particularly the QTc interval, are not associated with LCM.

However, available data are mostly from short-term use (ie, less than 6 months), and are collected from highly selected patients enrolled in clinical trials. No data about the use of LCM in clinical practice have been published. In addition, data of more than 10,000 patients and long-term application of 12 or more months are needed to assess more reliably the frequency and severity of rare side effects. Until data from postmarketing studies, currently ongoing monotherapy studes, ${ }^{48}$ and experiences from clinical practice are available, the role of LCM within the spectrum of AEDs remains unclear.

LCM has shown analgesic effects in preclinical studies $^{49}$ and seemed promising in phase I and phase II studies for neuropathic pain in diabetic polyneuropathy. There was some effect of LCM also in the following large randomized controlled phase III studies. However, this effect failed to reach statistical significance for the primary outcome parameters in the $200 \mathrm{mg} /$ day arm and in the $600 \mathrm{mg} /$ day arms in all of the 3 phase III studies, ${ }^{38-40}$ and in the $400 \mathrm{mg} /$ day arm in 1 study. ${ }^{40}$ As a consequence, LCM has not been approved for this indication. It is unknown if there will be further trials for neuropathic or other forms of pain.

The intravenous solution of LCM is approved for temporal substitution purposes only. Status epilepticus is a neurological emergency that frequently requires rapid treatment of unresponsive patients with intravenous application of anticonvulsive agents. However, only few of the available drugs are explicitly licensed for treatment of status epilepticus, and most of them such as phenytoin or thiopental carry a high risk of adverse event or require artificial ventilation, or both. Therefore, any AED that is available as intravenous formulation is a potential candidate for treatment of status epilepticus, particularly if standard drugs fail or are unsuitable. Lacosamid iv solution is easy to handle, and has the same safety profile as its oral formulation. It is not surprising that it already has been used successfully as off-label therapy for status epilepticus..$^{50,51}$ However, prospective trials are needed to assess the efficacy and safety of LCM for this indication.

\section{Disclosure}

Dr. Kellinghaus has received honoraria and travel support from UCB, Sanofi-Aventis, Novartis, Janssen-Cilag, Eisai.

\section{References}

1. Fisher RS, van Emde BW, Blume W, et al. Epileptic seizures and epilepsy: definitions proposed by the International League Against Epilepsy (ILAE) and the International Bureau for Epilepsy (IBE). Epilepsia. 2005;46:470-472.

2. Berg AT. Epidemiologic aspects of Epilepsy. In: Wyllie E, Gupta A, Lachhwani DK (ed). The Treatment of Epilepsy-Principles and Practice. 4th ed., Philadelphia: Lippincott Williams \& Wilkins; 2006:109-116.

3. Keränen T, Riekkinen P. Severe epilepsy: diagnostic and epidemiological aspects. Acta Neurol Scand Suppl. 1988;117:7-14.

4. Kwan P,Brodie MJ. Early identification of refractory epilepsy. $N$ Engl J Med. 2000;342:314-319.

5. Bialer M. New antiepileptic drugs currently in clinical trials: is there a strategy in their development? Ther Drug Monit. 2002;24:85-90.

6. Cortes S, Liao ZK, Watson D, Kohn H. Effect of structural modification of the hydantoin ring on anticonvulsant activity. J Med Chem. 1985;28:601-606.

7. Andurkar SV, Stables JP, Kohn H. The anticonvulsant activities of N-benzyl 3-methoxypropionamides. Bioorg Med Chem. 1999;7:2381-2389.

8. Beyreuther BK, Freitag J, Heers C, et al. Lacosamide: a review of preclinical properties. CNS Drug Rev. 2007;13:21-42.

9. Choi D, Stables JP, Kohn H. Synthesis and anticonvulsant activities of N-benzyl-2-acetamidopropionamide derivatives. J Med Chem. 1996;39:1907-1916.

10. Hovinga CA. SPM-927 (Schwarz Pharma). IDrugs. 2003;6:479-485.

11. LeTiran A, Stables JP, Kohn H. Functionalized amino acid anticonvulsants: synthesis and pharmacological evaluation of conformationally restricted analogues. Bioorg Med Chem. 2001;9:2693-2708.

12. Errington AC, Coyne L, Stöhr T, Selve N, Lees G. Seeking a mechanism of action for the novel anticonvulsant lacosamide. Neuropharmacology. 2006;50:1016-1029. 
13. Lees G, Stöhr T, Errington AC. Stereoselective effects of the novel anticonvulsant lacosamide against 4-AP induced epileptiform activity in rat visual cortex in vitro. Neuropharmacology. 2006;50:98-110.

14. Errington AC, Stöhr T, Heers C, Lees G. The investigational anticonvulsant lacosamide selectively enhances slow inactivation of voltage-gated sodium channels. Mol Pharmacol. 2008;73:157-169.

15. Yoshimura T, Kawano Y, Arimura N, et al. GSK-3beta regulates phosphorylation of CRMP-2 and neuronal polarity. Cell. 2005;120:137-149.

16. Czech T, Yang JW, Csaszar E, et al. Reduction of hippocampal collapsin response mediated protein-2 in patients with mesial temporal lobe epilepsy. Neurochem Res. 2004;29:2189-2196.

17. Möddel G, Jacobson B, Ying Z, et al. The NMDA receptor NR2B subunit contributes to epileptogenesis in human cortical dysplasia. Brain Res. 2005;1046:10-23.

18. Horstmann R, Bonn R, Cawello W, Doty P, Rudd D. Basic clinical pharmacologic investigations of the new antiepileptic drug SPM 927. Epilepsia. 2002;43(Supp1 7):188.

19. Cawello W, Kropeit D, Schiltmeyer B, Hammes W, Horstmann R. Food does not affect the pharmacokinetics of SPM 927. Epilepsia. 2004;45(Supp1 7):307.

20. Thomas D, Scharfenecker U, Nickel B, et al. Low potential for drugdrug interaction of lacosamide. Epilepsia. 2006;47(Suppl 4):200.

21. Schiltmeyer B, Cawello W, Kropeit D, Hammes W, Horstmann R. Pharmacokinetics of the new antiepileptic drug SPM 927 in human subjects with different age and gender. Epilepsia. 2004;45(Suppl 7):313.

22. Cross SA, Curran MP. Lacosamide: in partial-onset seizures. Drugs. 2009;69:449-459.

23. Doty P, Rudd GD, Stoehr T, Thomas D. Lacosamide. Neurotherapeutics. 2007;4:145-148.

24. Horstmann R, Bonn R, Cawello W, Doty P, Rudd D. SPM 927 does not interact with valproic acid and carbamazepine. Epilepsia. 2003; 44(Suppl 9):97.

25. Schiltmeyer B, Kropeit D, Cawello W, Hammes W, Horstmann R. No interaction between lacosamide and metformin. J Pain. 2006;7:S63.

26. Ben Menachem E, Biton V, Jatuzis D, et al. Efficacy and safety of oral lacosamide as adjunctive therapy in adults with partial-onset seizures. Epilepsia. 2007;48:1308-1317.

27. Fountain N, French J, Priviteril MD. Harkoseride: safety and tolerability of a new antiepileptic drug (AED) in patients with refracotry partial seizures. Epilepsia. 2000;4 (Suppl 7):169.

28. Halasz P, Kalviainen R, Mazurkiewicz-Beldzinska M, et al. Adjunctive lacosamide for partial-onset seizures: Efficacy and safety results from a randomized controlled trial. Epilepsia. 2009;50:443-453.

29. Bialer M, Johannessen SI, Kupferberg HJ, et al. Progress report on new antiepileptic drugs: a summary of the Fifth Eilat Conference (EILAT V). Epilepsy Res. 2001;43:11-58.

30. Swinyard EA, Brown WC, Goodman LS. Comparative assays of antiepileptic drugs in mice and rats. J Pharmacol Exp Ther. 1952;106:319-330.

31. Stöhr T, Kupferberg HJ, Stables JP, et al. Lacosamide, a novel anticonvulsant drug, shows efficacy with a wide safety margin in rodent models for epilepsy. Epilepsy Res. 2007;74:147-154.

32. Barton ME, Klein BD, Wolf HH, White HS. Pharmacological characterization of the $6 \mathrm{~Hz}$ psychomotor seizure model of partial epilepsy. Epilepsy Res. 2001;47:217-227.

33. Duncan GE, Kohn H. The novel antiepileptic drug lacosamide blocks behavioral and brain metabolic manifestations of seizure activity in the $6 \mathrm{~Hz}$ psychomotor seizure model. Epilepsy Res. 2005;67:81-87.
34. Lothman EW, Williamson JM. Closely spaced recurrent hippocampal seizures elicit two types of heightened epileptogenesis: a rapidly developing, transient kindling and a slowly developing, enduring kindling. Brain Res. 1994;649:71-84.

35. Sachdeo R, Montouris G, Beydoun A, et al. An open-label, maximum tolerated dose trial to evaluate oral SPM 927 as adjunctive therapy in patients with partial seizures. Neurology. 2003;6(Suppl 1):A433.

36. Chung SS, Sperling M, Biton V, et al. Lacosamide: efficacy and safety as oral adjunctive treatment for partial-onset seizures. Epilepsia. 2007;4(Suppl 6):Poster 3.197.

37. Rosenfeld WE, Montouris G, Whitesides J, Doty P, Rudd D. Long-term safety and efficacy of SPM 927 as adjunctive therapy in subjects with partial seizures: 24-week follow-up. Epilepsia. 2003;4(Suppl 9):262.

38. Shaibani A, Fares S, Selam JL, et al. Lacosamide in painful diabetic neuropathy: an 18-week double-blind placebo-controlled trial. J Pain. 2009;

39. Wymer JP, Simpson J, Sen D, Bongardt S. Efficacy and safety of lacosamide in diabetic neuropathic pain: an 18-week double-blind placebocontrolled trial of fixed-dose regimens. Clin J Pain. 2009;25:376-385.

40. Ziegler D, Bongardt S, Koc B, Thierfelder S. Efficacy and safety of Lacosamide in the treatment of neuropahtic pain attributed to distal diabetic neuropathy. Epilepsia. 2005;46(Suppl 8):187.

41. Graf R, Frye W, Simpson J, Jay G. Lacosamide in long-term treatment of painful diabetic neuropathy (DNP). Eur J Neurol. 2007;14(Suppl 1):260.

42. Rosenfeld W, Fountain N, Kaubrys G, Heinzen L, McShea C. Lacosamide: an interim evaluation of the long-term safety and efficacy as oral adjunctive therapy in subjects with partial-onset seizures. Epilepsia. 2007;48(Suppl 6):Poster.

43. Cawello W, Horstmann R, Doty P, et al. No influence of the new antiepileptic drug SPM 927 on th ECG time intervals QTc and PR. [poster] Epilepsia. 2004;45(Suppl 7):Poster 1.265.

44. Biton V, Rosenfeld WE, Whitesides J, et al. Intravenous lacosamide as replacement for oral lacosamide in patients with partial-onset seizures. Epilepsia. 2008;49:418-424.

45. Kropeit D, Schiltmeyer B, Cawello W, Hammes W, Horstmann R. Bioequivalence of short-time infusions compared to oral administration of lacosamide. Epilepsia. 2004;45(Suppl 7):123.

46. Thomas D, Nickel B, Cawello W, Hammes W, Horstmann R. Bioequivalence of Short-time infusions compared to oral administration of lacosamide. Epilepsia. 2006;47(Suppl 4).

47. Krauss G, Ben Menachem E, Mamenskiene R, et al. Intravenous lacosamide as replacement for oral lacosamide in subjects with partial seizures: a multicenter, open-label, inpatient trail examining safety and tolerability of 10- and 15-minute infusion durations. Epilepsia. 2007;48 (Suppl 6):3.303.

48. Krämer G, Heinzl S. Lacosamid. Stuttgart: Ligatur; 2008.

49. Sheets PL, Heers C, Stoehr T, Cummins TR. Differential block of sensory neuronal voltage-gated sodium channels by lacosamide [(2R)2-(acetylamino)-N-benzyl-3-methoxypropanamide], lidocaine, and carbamazepine. J Pharmacol Exp Ther. 2008;326:89-99.

50. Berning S, Kellinghaus C. Intravenous lacosamide for treatment of status epilepticus. Epilepsia. 2009;50(Suppl 6):49.

51. Kellinghaus C, Berning S, Besselmann M. Intravenous lacosamide as successful treatment for nonconvulsive status epilepticus after failure of first-line therapy. Epilepsy Behav. 2009;14:429-431.
Therapeutics and Clinical Risk Management

\section{Publish your work in this journal}

Therapeutics and Clinical Risk Management is an international, peerreviewed journal of clinical therapeutics and risk management, focusing on concise rapid reporting of clinical studies in all therapeutic areas, outcomes, safety, and programs for the effective, safe, and sustained use of medicines. This journal is indexed on PubMed Central, CAS,

\section{Dovepress}

EMBase, Scopus and the Elsevier Bibliographic databases. The manuscript management system is completely online and includes a very quick and fair peer-review system, which is all easy to use. Visit http://www.dovepress.com/testimonials.php to read real quotes from published authors. 